\title{
Government Debt and the Returns to Innovation
}

\author{
M. Max Croce* \\ Thien T. Nguyen ${ }^{\dagger}$ \\ Steve Raymond $d^{\ddagger} \quad$ Lukas Schmid ${ }^{\S}$
}

February 2016

Preliminary and Incomplete

\begin{abstract}
Elevated levels of US government debt in the aftermath of the great recession have raised concerns about their effects on long-term growth prospects. By empirically identifying measures of government indebtedness as risk factors priced in stock returns, we document and theoretically evaluate a novel risk channel at work shaping this link. In the cross-section, stocks earn positive premia for their exposure to movements in government debt, while these predict high stock returns going forward in the time series. A substantial return spread between the most and the least innovative firms is increasing in the debt-to-gdp ratio. We show that rises in the cost of capital for innovation-intensive firms associated with elevated government debt bring about declines in $R \& D$ activity and economic growth. We interpret these findings through the lens of a production-based asset pricing model with endogenous innovation and fiscal policy. The model emphasizes the role of political and fiscal uncertainty in shaping the empirical relationships.
\end{abstract}

Keywords: Government debt, fiscal uncertainty, political uncertainty, innovation, R\&D, endogenous growth, risk factors, cross-section of stock returns, predictability

*University of North Carolina

${ }^{\dagger}$ Ohio State University

$\ddagger$ University of North Carolina

${ }^{\S}$ Duke University 


\section{Introduction}

Fiscal stabilization policies implemented in response to the recent great recession have led to a surge of government debt across the globe. A common concern is that the required associated budget consolidation processes will come at the cost of dimmer long-run growth prospects. This concern is based on expectations of higher future tax pressure, on rises in average inflation through attempts to inflate debt away, as well as on the political uncertainty surrounding the restoration of budget balance. In this paper, we empirically and theoretically highlight a novel and distinct mechanism shaping the link between public debt and future growth, namely a risk channel. More specifically, we identify measures of government debt as risk factors priced in the cross-section and time series of stock returns.

Our empirical investigation starts by documenting that our preferred measure of government indebtedness, namely simply the debt-to-gdp ratio, significantly predicts higher future aggregate stock returns at longer horizons, even when controlling for standard predictors such as price-dividend ratios and market volatility. In other words, investors perceive episodes of high government debt as bad times. This finding suggests that government debt should be a risk factor priced in the cross-section of stock returns as investors are hesitant to incur losses on stocks in such bad times. We confirm this intuition by means of standard cross-sectional asset pricing tests. We find that portfolios of stocks exhibiting higher exposure to movements in government debt (higher debt betas, in other words) earn higher average returns, even after controlling for standard risk factors. This estimated positive price of risk of government debt is robust to the choice of major test assets, such as Fama-French or industry portfolios.

Our central empirical finding is that portfolios sorted on firms' innovative intensity earn a premium for their exposure to movements in government debt, even after controlling for standard risk factors. Moreover, we show that this premium rises when government debt increases, as our risk factor also predicts higher stock returns on innovation-sorted portfolios going forward in the

time series. In other words, our asset pricing tests suggest that rises in government debt increase the cost of capital for innovative firms. Critically, we document that these movements in the cost of capital of innovative firms in response to surges in government debt are associated with slowdowns 
in innovative activity, and thus economic growth.

To interpret and rationalize our empirical findings, we develop a quantitative model of a stochastic production economy in which endogenous innovation drives growth prospects. The government finances expenditures by issuing debt and levying distortionary taxes on corporate profits, which affects corporate investment and innovation, and thus growth. Shocks to productivity, government expenditures and debt are reflected in corporate policies, and, in general equilibrium, in agents' stochastic discount factor. The resulting conditional three-factor model generates high average stock returns, and a realistic premium on innovative stocks, in line with the empirical evidence. Within the context of the model, this premium reflects elevated exposure to shocks to the government's debt policy, that is, a measure of fiscal uncertainty. Our model thus highlights the role of policy uncertainty in the determination of risk premia.

Naturally, in our general equilibrium production economy, there is a tight link between risk premia and real outcomes. We therefore examine the joint determination of debt risk premia on innovative firms and innovation, and show that in the model increases in premia on innovative firms are associated with declines in innovative activity, and thus long-run economic growth. Our model thus rationalizes the risk channel that links government debt and growth uncovered in our empirical work.

Related Literature Our paper contributes to several strands of literature. Our empirical asset pricing tests are in the spirit of recent and classic work emphasizing return predictability in the cross-section and the time series. A non-exhaustive list of important papers on cross-sectional return predictability includes Bansal, Dittmar, and Lundblad (2005), Carhart (1997), Cochrane (1994), Fama and French (1992), Pastor and Stambaugh (2003), and Hou, Xue and Zhang (2015), to name a few. Time-series predictability has been explored in Campbell and Shiller (1988), Cochrane (2007), Lettau and Ludvigson (2004), and Koijen, Lustig and Van Nieuwerburgh (2015), for example. Adding to this literature, we document a simple, and economically meaningful predictor both in the cross-section and the time series, namely the government debt to gdp ratio.

Our paper shares its emphasis on innovation and its links with asset pricing and growth with a growing literature investigating these relationships. Recent examples emphasizing links between 
innovation and cross-sectional and time-series patterns in stock returns are Garleanu, Kogan, and Panageas (2012), Kogan, Papanikolaou and Stoffman (2014), Kogan, Seru, Stoffman, and Papanikolaou (2015), Kung and Schmid (2015), Corhay, Kung, and Schmid (2015), and Gavazzoni and Santacreu (2015). Our paper focuses on the role of government debt and taxation shaping the empirical evidence. In this sense, our paperis related to Croce, Nguyen and Schmid (2012), who introduce fiscal policy into a simple stochastic endogenous growth model, similar to us.

Our model highlights the role of fiscal uncertainty in shaping the empirical evidence. In this regard, the paper is related to the growing literature on policy uncertainty and asset markets. Recent papers examining that link include Pastor and Veronesi (2012, 2013), Croce, Kung, Nguyen, and Schmid (2012), Brogaard and Detzel (2015), and Kelly, Pastor, and Veronesi (2016). In contrast to these contributions, we examine the role of uncertainty about the fiscal stance for the cross-section and the time-series of stock returns.

More broadly, our paper shares its focus with the growing literature on asset pricing in general equilibrium models with production. Papers that use habit preferences include Jermann (1998) and Boldrin, Christiano, and Fisher (2001). More recently, Tallarini (2000), Campanale, Castro, and Clementi (2008), Kuehn (2008, 2009), Ai (2010), Kaltenbrunner and Lochstoer (2010), Ai, Croce, and Li (2013), Croce (2014) explore endogenous long-run consumption risks in real business cycle models with recursive preferences. Gourio $(2012,2013)$ examines disaster risks.

Methodologically, our theoretical work builds on recent papers by Comin and Gertler (2006) and Comin, Gertler, and Santacreu (2009). Building on the seminal work of Romer (1990) and Grossman and Helpman (1991), these papers integrate innovation-based endogenous growth models into the workshorse real business cycle model of macroeconomics.

This paper is structured as follows. In section 2, we provide motivating empirical evidence linking movements in government debt to gdp ratio to cross-sectional and time series patterns in stock returns. We develop a model to rationalize these findings in section 3 . Section 4 reports quantitative implications of the model obtained through calibration. Section 5 concludes. 


\section{Empirical Analysis}

We start by providing empirical evidence on the links between government debt and stock returns by means of standard empirical asset pricing tests. First, we outline the data we use, and then go on to discuss our tests and results.

\subsection{Data}

We use stock return data from CRSP and fundamental accounting data from COMPUSTAT to construct a combined panel at the quarterly frequency from 2Q1966-4Q2013. Fama-French factors and industry portfolios are constructed from Kenneth French's website. We source quarterly macroeconomic data from the Federal Reserve Bank of St. Louis, specifically government debt defined as Federal Debt: Total Public Debt and quarterly seasonally adjusted GDP. Price/dividend data is sourced from Robert Shillers website, and quarterly market volatility is defined as the sum of squared monthly returns for a given quarter.

Each calendar year stock return portfolios are constructed by sorting firms based on the ratio R\&D expense to total assets, our primary proxy for R\&D intensity. We group firms into portfolios based on approximately even market capitalization per portfolio (i.e. form 10 sorted portfolios where each portfolio constitutes approximately $10 \%$ of the total market capitalization in that period). We rebalance these portfolios once a year based on previous year's R\&D intensity proxy, and record value-weighted return performance for the subsequent year.

\section{$2.2 \quad$ Asset Pricing Tests}

\subsubsection{Cross-sectional Tests}

We present our baseline cross-sectional asset pricing tests in table 1. The table reports both factor loadings of test assets and the estimated cross-sectional slope coefficient, or in other words, the factor risk premium. Rather than performing two-step Fama-Macbeth cross-sectional regressions, we use GMM to estimate both factor loadings and factor risk premia simultaneously. The test assets in our baseline case, reported in tables 1, are portfolios constructed by sorting stocks along their 
innovative activity, measured here as the R\&D intensity. We split our sample in three portfolios, low, middle, and high R\&D intensity portfolios, and construct a high-minus-low, HML, as the difference between the last and the first. Our risk factor of interest is simply the debt to gdp ratio. However, we want to control for exposure to standard risk factors such as the Fama-French 3 factors, so that our main results are based on using residuals from Fama-French regressions.

The results in table 1 are statistically and economically meaningful. In our procedure, we obtain positive loadings of th innovation-sorted on portfolios on the debt risk factor. Its factor risk premium is estimated to be positive and statistically significantly different from zero. Note that this is obtained controlling for the Fama-French 3 factors. While all positive, the factor loadings of the test portfolios display an interesting pattern in that the HML portfolio has a loading which is positive, and statistically different from zero. In other words, our results indicate that more innovative firms have a higher exposure to movements in the government debt risk factor. Given the positive price of risk, this implies that innovative firms earn a premium for their exposure, so that their cost of capital is higher.

We provide additional robustness test further confirming our results, in tables 2 and 3 . Here we expand our set of test assets in the GMM estimation. In table 2, we include Fama-French industry portfolios as test assets. Here we explicitly include the fama-French factors in the estimation. Our results are not qualitatively affected by expanding our test assets along this line: We confirm a positive and signficant factor risk premium for government debt, and find that more innovative firms are significantly more exposed, as measured by the HML exposure. On other words, they do also earn a premium for their exposure in this specification. Moreoever, we report economically meaningful and intuitive factor loadings for te industry portfolios.

Simply including the Fama-French portfolios does not change this result, as table 3 reports. Our results thus suggest that governmeent debt to gdp is a risk factor priced in the cross-section of returns, controlling for the standard risk factors. We next examine the dynamics of this exposure by means of time series tests. 


\subsubsection{Time-series Tests}

In tables 4 and 5, we report results from both univariate and multivariate predictive return regressions at various horizons. We show results both at the market level as well as for various portfolios sorted on firms' innovation intensity, and use standard predictors such as price-dividend ratios and market volatility in addition to debt to gdp. Our main results are in table 4, documenting multivariate results.

The results first confirm that in our sample both price-dividend ratios and market volatility are significant predictors of future market returns, with the standard signs. High price-dividend ratios and low market volatility predict low market returns going forward. More interestingly, our results document that including the debt to gdp ratio as a predictor increases the predictive power of the regressions. We find that government debt predicts aggregate market returns significantly with a positive sign, in this mutivariate design. This suggests that times of high government indebtedness correspond to times of high risk premia, and are thus viewed as bad times from the perspective of investors. This result hence identifies a novel and economically meaningful signifcant predictor of future market returns.

We next dissect the predictive evidence further at the portfolio level, and again focus on portfolios of stocks sorted along their innovative intensity, including a high minus low, HML, portfolio. Our main result here is that in this multivariate setup, government debt highly statistically significantly predicts higher returns going forward on both the high innovation intensity and the HML portfolio. These findings are robust across all forecast horizons, and in fact its significance is increasing with horizon. This is an economically important result. Not only are premia on innovative firms rising with government debt, but also the spread between the premia on the most and the least innovative firms are rising. While our cross-sectional tests have shown that exposure to government requires a premium on innovative stocks, the time series tests document that this premium is time-varying and rising with the degree of government indebtedness. In other words, this finding implies that the cost of capital for innovative firms increases with government debt, and more so than for less innovative firms. To the extent that innovative firms are seen as engines of growth, such a rise of their cost of capital may have implications for the real economy. We will examine this intuition in the next paragraph. 
Table 5 reports similar results, obtained in a univariate setting. Perhaps not surprisingly, the predictive power of government debt for future market returns, and future returns on innovative stocks becomes even stronger in this case. In contrast, we note that price-dividend ratios display very little predictive power for R\&D sorted portfolios, as well as the HML portfolio, while market volatility does, especially for innovative stocks. This is in line with the notion that innovative firms are growth option intensive, and therefore sensitive to movements in volatility.

\subsection{Government Debt and Growth}

We now investigate the notion discussed above that movements in innovative firms' cost of capital in response to swings in government debt affect the real economy, and perhaps, economic growth. Tables 6 and 7 provides some evidence to these effects.

Table 6 demonstrates that movements in government debt are indeed associated with a decline with in firms' R\&D intensity in the data, across firms sorted on innovative activity. This obtains controlling for firm-level variables such as Tobin's Q. We find a statistically significant negative link especially for the highest and the lowest R\&D intensity firms, and especially their spread. While this is no more than suggestive evidence, we will use the model to be developed in the next section to interpret this piece of evidence.

Table 7 provides similar suggestive evidence by reporting results of long-horizon predictive regressions of gdp growth, using debt-to-gdp, market volatility, and price-dividend ratios as predictors. Clearly, movements in the debt to gdp ratio are associated with declines in gdp growth at very long horizons, and statistically significantly so. Remarkably, at shorter horizons these negative effects are swamped by the negative impact of market volatilty. At longer horizons the impact of volatility disappears and is dominated by the predictive power of government indebtedness. The effects of the price-dividend ratio are small and not statistically distinguishable from zero.

These patterns linking debt, innovation and returns motivate us to develop a formal model that allow us to move beyond simple correlations, albeit, of course, trough the lens and the restrictions of the model. 


\section{An Asset-Pricing Model with Debt and Innovation}

To link public debt and innovation, we develop a stochastic endogenous growth model in which a government finances exogenous expenditures by issuing public debt and taxing firms. Our baseline framework nests an innovation-based stochastic growth model augmented with convex adjustment costs and recursive Epstein-Zin preferences, as in Kung and Schmid (2015), with an account of the government's fiscal stance as in Croce, Nguyen, and Schmid (2012) . In the model, rather than assuming exogenous technological progress, sustained growth instead arises through the accumulation of patented intermediate goods (henceforth patents) that facilitate the production of a final consumption good. New patents are created through innovation requiring investment in research and development $(\mathrm{R} \& \mathrm{D})$ and can be stored. In this model, therefore, patents represent an endogenous stock of intangible capital. Because the model features two endogenous capital stocks, namely physical and intangible, respectively, it gives rise to a non-trivial endogenous cross-section of firms, and thus returns.

We start by introducing the government's fiscal stance, and proceed by describing in detail the production sector and the innovation process in our economy. We then present the household sector and define the general equilibrium.

\subsection{Government}

We assume that the government faces an exogenous and stochastic expenditure stream, $\Gamma_{t}$, that evolves as follows:

$$
\frac{\Gamma_{t}}{G D P_{t}}=\frac{1}{1+e^{-g y_{t}}}
$$

where

$$
g y_{t}=\left(1-\rho_{\Gamma}\right) \overline{g y}+\rho_{\Gamma} g y_{t-1}+\epsilon_{\Gamma, t}, \quad \epsilon_{\Gamma, t} \sim N\left(0, \sigma_{\Gamma}^{2}\right) .
$$

This specification ensures that $\Gamma_{t} \in\left(0, G D P_{t}\right)$ for all date $t$, and it enables us to replicates key features of the expenditure-to-output ratio observed in the U.S. data. In most of our analysis, we focus only on the expenditure component of total public liabilities and abstract away from entitlements. $G D P_{t}$ arises endogenously from the production process and we describe its components in 
detail below.

We assume that the government can finance these expenditures by raising public debt, or by levying distortionary profit taxes on corporations, at a possibly time-varying rate $\tau_{t}$. When doing so, the government is subject to the following budget constraint

$$
B_{t}=\left(1+r_{f, t-1}\right) B_{t-1}+\Gamma_{t}-T_{t}
$$

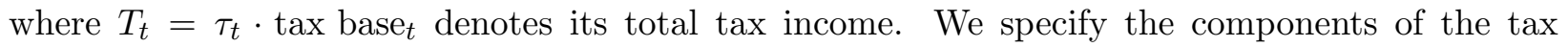
base below. The government chooses the mix between taxation and deficit by means of simple, implementable and plausible fiscal rules, in the spirit of

In this paper we focus on the tax regime where we allow for tax smoothing and let the government adjust its fiscal stance according to prevailing macroeconomic conditions. We focus on two aspects of tax smoothing, namely the persistence and intensity of swings in the tax rate. We specify the government's policy in terms of a debt management rule, with tax rates implied by the budget constraint, as follows:

$$
\begin{aligned}
\frac{B_{t}}{G D P_{t}} & =\left(1-\rho_{B}\right) \mu_{B}+\rho_{B} \frac{B_{t-1}}{G D P_{t-1}}+\phi_{B} \cdot \epsilon_{t}^{B}, \\
\epsilon_{t}^{B} & =A_{\omega} \epsilon_{\omega, t}+A_{\Gamma} \epsilon_{\Gamma, t}+A_{\phi} \epsilon_{\phi, t},
\end{aligned}
$$

where $A_{z}, A_{\Gamma}$ and $A_{\phi}$ are constant. We model $\epsilon_{t}^{B}$ in this way to capture the fact that government conducts fiscal policies in responding to fundamental shocks: TFP $\epsilon_{\omega, t}$ and government spending $\epsilon_{\Gamma, t}$. In addition the debt policy rule contains a pure policy shock $\epsilon_{\phi, t}$. We will show later that this is essential in bringing the model closer to the data. $\mu_{B}$ captures the long-run level of debt; $\phi_{B}$ determines the intensity of the government response to shocks; and $\rho_{B} \in(0,1)$ is a measure of the speed of repayment of debt, i.e., the higher the value of $\rho_{B}$, the slower the repayment of debt relative to output.

This parsimonious specification has two main advantages. First, the condition $\rho_{B}<1$ guarantees stationarity of the debt-output ratio. In the language of Bi and Leeper (2010), our rule in equation (3) anchors expectations about future debt and rules out unstable paths. Overall, this 
specification replicates key empirical properties of the U.S. debt-output ratio.

\subsection{Production}

The production process involves three sectors. The final consumption good is produced in a competitive sector, namely the final goods sector, using physical capital, labor and patents. Stationary shocks drive stochastic fluctuations in the production of the final consumption good. Patents are produced in the intangible sector, where firms have monopoly power. New patents are created by means of innovation through $R \& D$ in the innovation sector, which is competitive again. Regarding taxation, we assume that profits in both the final goods sector and the intangible sector are taxed at a rate $\tau_{t}$.

Absent patents, decreasing returns to physical capital in the production function would imply that growth ceases in the long run, given stationary shocks - a standard result from the Solow growth model. In our setup, in contrast, acquiring patents from the intangible sector facilitates production for a given stock of physical capital, allowing the final goods firm to grow and creating the latter's demand for patents. That demand is met by the intangible sector, which earns profits from selling patents to the final good firm by charging a markup over its marginal costs. Monopoly power is important as the associated profits provide the rents for creating new patents. The innovation sector sells a newly developed patent to the intangible sector at the competitive price, namely the present value of its profits.

Sustained growth obtains in this economy because the final goods firm's demand for patents creates new profit opportunities in the intangible sector and thus raises the incentives to create new patents through innovation. These new patents increase the efficiency of physical capital, boosting investment and thus, in turn, creating even more demand for patents. In this setup, taxes distort firms' investment and innovation decisions, and hence the rate and the dynamics of growth.

Final Goods Sector There is a representative firm that uses capital $K_{t}$, labor $L_{t}$ and a composite of patents $G_{t}$ to produce the final (consumption) good according to the production technology

$$
Y_{t}=\left(K_{t}^{\alpha}\left(\Omega_{t} L_{t}\right)^{1-\alpha}\right)^{1-\xi} G_{t}^{\xi}
$$


where the composite $G_{t}$ is defined as

$$
G_{t} \equiv\left[\int_{0}^{N_{t}} X_{i, t}^{\nu} d i\right]^{\frac{1}{\nu}}
$$

$X_{i, t}$ is the quantity of patent $i \in\left[0, N_{t}\right]$, where $N_{t}$ is the measure of patents in use at date $t$, and $\alpha$ is the physical capital share, $\xi$ is the intangible capital share, and the elasticity of of substitution between patents is $\frac{1}{1-\nu}$ with $\nu<1$. We will interpret $N_{t}$ as the stock of intangible capital.

We introduce uncertainty into the model by means of an exogenous stochastic process $\Omega_{t}$ affecting the level of output. Importantly, $\Omega_{t}$ is assumed to follow a stationary Markov process by specifying that $\Omega_{t}=e^{a_{t}}$, and $a_{t}=\rho a_{t-1}+\epsilon_{\omega, t}$, with $\epsilon_{\omega, t} \sim N\left(0, \sigma^{2}\right)$ and $\rho<1$. Because of the stationarity of the forcing process, sustained growth will arise endogenously from the development of new patents. We will describe how new patents are developed by means of innovation below.

The firm's objective is to maximize shareholder value. This can be formally stated as

$$
\max _{\left\{I_{t}, L_{t}, K_{t+1}, X_{i, t}\right\}_{t \geq 0, i \in\left[0, N_{t}\right]}} E_{0}\left[\sum_{t=0}^{\infty} M_{t} D_{t}\right]
$$

where the firm's dividends are

$$
D_{t}=\left(1-\tau_{t}\right)\left[Y_{t}-W_{t} L_{t}-\int_{0}^{N_{t}} P_{i, t} X_{i, t} d i\right]-I_{t}
$$

Here, $M_{t}$ is the stochastic discount factor, $I_{t}$ is investment in physical capital, $W_{t}$ is the wage rate, and $P_{i, t}$ is the price per unit of patent $i$. The last term captures the costs of buying patents at time t. Prices $P_{i, t}$ are set by patent producers in the intangible sector, while the stochastic discount factor and the wage rate are determined in the general equilibrium and are all taken as given by the final goods firm. Note that the final goods firm's profits are taxed at the rate $\tau_{t}$.

In line with the literature on production-based asset pricing, we assume that investment is subject to convex capital adjustment costs, so that the physical capital stock evolves as

$$
K_{t+1}=(1-\delta) K_{t}+\Lambda\left(\frac{I_{t}}{K_{t}}\right) K_{t} .
$$


Here, $\delta$ is the depreciation rate of physical capital and $\Lambda(\cdot)$ the capital adjustment cost function ${ }^{1}$.

Intangible Sector Patents are produced in the intangible sector. Patent producers have monopoly power. Given the demand schedules set by the final good firm, monopolists producing the patents set the prices $P_{i, t}$ in order to maximize their after tax profits $\left(1-\tau_{t}\right) \Pi_{i, t}$. Patent producers transform one unit of the final good in one unit of their patent. In this sense production is "roundabout" in that monopolists take final good production as given as they are tiny themselves. This fixes the marginal cost of producing one patent at unity.

Thus, monopolists solve the following static profit maximization problem each period

$$
\max _{P_{i, t}} \Pi_{i, t} \equiv \max _{P_{i, t}} P_{i, t} \cdot X_{i, t}\left(P_{i, t}\right)-X_{i, t}\left(P_{i, t}\right)
$$

The value $V_{i, t}$ of owning exclusive rights to produce patent $i$ is equal to the present discounted value of the current and future monopoly profits, so that

$$
V_{i, t}=\left(1-\tau_{t}\right) \Pi_{t}+(1-\phi) E_{t}\left[M_{t+1} V_{i, t+1}\right]
$$

where $\phi$ is the probability that a patent becomes obsolete. This asset price is important in our model, as it provides the payoff to creating new patents by means of innovation, as we describe next. This highlights the importance of monopoly power, as the associated profits provide the rents to innovation.

Innovation Sector Innovators develop new patents used in the production of final output. They do so by conducting research and development, using the final good as input at unit cost. These newly developed patents can be sold to patent producers. Assuming that this market is competitive, the price of a new patent will equal its value to the patent producer, namely $V_{i, t}$.

\footnotetext{
${ }^{1}$ We specify $\Lambda(\cdot)$ as in Jermann (1998), $\Lambda\left(\frac{I_{t}}{K_{t}}\right) \equiv \frac{\alpha_{1}}{\zeta}\left(\frac{I_{t}}{K_{t}}\right)^{\zeta}+\alpha_{2}$. Here, $\frac{1}{1-\zeta}$ represents the elasticity of the investment rate with respect to Tobin's Q. The parameters $\alpha_{1}$ and $\alpha_{2}$ are set so that there are no adjustment costs in the deterministic steady state.
} 
We link the evolution of the intangible capital stock $N_{t}$, to innovation as

$$
N_{t+1}=\vartheta_{t} S_{t}+(1-\phi) N_{t}
$$

where $S_{t}$ denotes R\&D expenditures (in terms of the final good) and $\vartheta_{t}$ represents the productivity of the $\mathrm{R} \& \mathrm{D}$ sector that is taken as exogenous by the $\mathrm{R} \& \mathrm{D}$ sector. In a similar spirit as Comin and Gertler (2006), we assume that this technology coefficient involves a congestion externality effect

$$
\vartheta_{t}=\frac{\chi \cdot N_{t}}{S_{t}^{1-\eta} N_{t}^{\eta}}
$$

where $\chi>0$ is a scale parameter and $\eta \in[0,1]$ is the elasticity of new patents with respect to R\&D. This specification captures the notion that concepts already discovered make it easier to come up with new ideas, $\partial \vartheta / \partial N>0$, and that $\mathrm{R} \& \mathrm{D}$ investment has decreasing marginal returns, $\partial \vartheta / \partial S<0^{2}$.

\subsection{Household}

The household sector is standard. The representative household has Epstein-Zin preferences defined over consumption:

$$
U_{t}=\left\{(1-\beta) C_{t}^{\theta}+\beta\left(E_{t}\left[U_{t+1}^{1-\gamma}\right]\right)^{\frac{\theta}{1-\gamma}}\right\}^{\frac{1}{\theta}}
$$

where $\gamma$ is the coefficient of relative risk aversion and $\psi \equiv \frac{1}{1-\theta}$ is the elasticity of intertemporal substitution. When $\psi \neq \frac{1}{\gamma}$, the agent cares about news regarding long-run growth prospects. We will assume that $\psi>\frac{1}{\gamma}$ so that the agent has a preference for early resolution of uncertainty and dislikes shocks to long-run expected growth rates.

The household maximizes utility by participating in financial markets and by supplying labor. Specifically, the household can take positions $\mathcal{Z}_{t}$ in the stock market, which pays an aggregate

\footnotetext{
${ }^{2}$ Similarly, this congestion externality can be thought of as giving rise to adjustment costs to investment in intangible capital, that is, $\mathrm{R} \& \mathrm{D}$. We will later see that the optimality condition for $\mathrm{R} \& \mathrm{D}$ is $\frac{1}{\vartheta_{t}}=E_{t}\left[M_{t+1} V_{t+1}\right]$, equating the marginal cost of creating a new patent with its marginal benefit. Absent the congestion externality, this boils down to $1=E_{t}\left[M_{t+1} V_{t+1}\right]$, a result analogous to Q-theory, in which case the absence of adjustment cost fixes marginal $\mathrm{Q}$ at unity.
} 
dividend $\mathcal{D}_{t}$, and in the bond market, $B_{t}$. Accordingly, the budget constraint of the household becomes

$$
C_{t}+\mathcal{Q}_{t} \mathcal{Z}_{t+1}+B_{t+1}=W_{t} L_{t}+\left(\mathcal{Q}_{t}+\mathcal{D}_{t}\right) \mathcal{Z}_{t}+\left(1+r_{t}\right) B_{t}
$$

where $\mathcal{Q}_{t}$ is the stock price, $r_{t}$ is the risk free rate, $W_{t}$ is the wage and $L_{t}$ denotes hours worked.

We assume that stocks are claims to all the production sectors, namely the final good sector, the intangible sector, as well as the research and development sector. Accordingly, we define the aggregate dividend as the net payout from the production sector

$$
\mathcal{D}_{t}=D_{t}+\int_{0}^{N_{t}} \Pi_{i, t} d i-S_{t}
$$

\subsection{Equilibrium and Asset Prices}

An equilibrium is a set of sequences of prices and quantities such that i) quantities solve producers' and the household's optimization problems and ii) prices are such that the markets clear. Moreover, we focus on a symmetric equilibrium in which all patent producers are identical. In the following, we describe the most important equilibrium conditions, while we defer the complete list of all relationships characterizing the equilibrium to appendix B.

The final good firm's optimality conditions are mostly standard. Denoting by $q_{t}=\frac{1}{\Lambda_{t}^{\prime}}$ the shadow value of physical capital, the first order condition for investment in physical capital is

$$
1=E_{t}\left[M_{t+1}\left\{\frac{1}{q_{t}}\left(\left(1-\tau_{t+1}\right) \alpha(1-\xi) \frac{Y_{t+1}}{K_{t+1}}+q_{t+1}(1-\delta)-\frac{I_{t+1}}{K_{t+1}}+q_{t+1} \Lambda_{t+1}\right)\right\}\right]
$$

On the other hand, the final good firm's demand for patent $i$ is determined by

$$
P_{i, t}=\left(K_{t}^{\alpha}\left(\Omega_{t} L_{t}\right)^{1-\alpha}\right)^{1-\xi} \frac{\xi}{\nu}\left[\int_{0}^{N_{t}} X_{i, t}^{\nu} d i\right]^{\frac{\xi}{\nu}-1} \nu X_{i, t}^{\nu-1}
$$

where it takes the price $P_{i, t}$ as given. The latter is set by the monopolistically competitive producer of patent $i$. In a symmetric equilibrium, the monopolistically competitive characterization of the 
intangible sector a la Dixit and Stiglitz (1977) implies

$$
X_{i, t} \equiv X_{t}, \quad \text { and } \quad P_{i, t} \equiv P_{t}=\frac{1}{\nu}
$$

That is, each patent producer charges a markup $\frac{1}{\nu}>1$ over unit marginal cost, so that profits are

$$
\Pi_{i, t} \equiv \Pi_{t}=\left(\frac{1}{\nu}-1\right) X_{t}
$$

with $X_{t}=\left(\xi \nu\left(K_{t}^{\alpha}\left(\Omega_{t} L_{t}\right)^{1-\alpha}\right)^{1-\xi} N_{t}^{\frac{\xi}{\nu}-1}\right)^{\frac{1}{1-\xi}}$. Profits are thus procyclical.

Discounted future profits on patents are the payoff to innovation, so that, since the R\&D sector is competitive, the optimality condition for $\mathrm{R} \& \mathrm{D}$ investment becomes

$$
E_{t}\left[M_{t+1} V_{t+1}\right]\left(N_{t+1}-(1-\phi) N_{t}\right)=S_{t}
$$

which says that the expected sales revenues equals costs, or equivalently, at the margin, $\frac{1}{\vartheta_{t}}=$ $E_{t}\left[M_{t+1} V_{t+1}\right]$. By pinning down the amount of $\mathrm{R} \& \mathrm{D}$ investment, this condition is crucial in this model, as it ultimately determines the equilibrium growth rate of the economy. Importantly, the procyclicality of profits will be reflected in R\&D investment.

The stochastic discount factor in the economy is given by

$$
M_{t+1}=\beta\left(\frac{C_{t+1}}{C_{t}}\right)^{\theta-1}\left(\frac{U_{t+1}}{E_{t}\left(U_{t+1}^{1-\gamma}\right)^{\frac{1}{1-\gamma}}}\right)^{1-\gamma-\theta} .
$$

where the second term, involving continuation utilities, captures preferences concerning uncertainty about long-run growth prospects. Optimality implies the following asset pricing conditions:

$$
\begin{aligned}
Q_{t} & =E_{t}\left[M_{t+1}\left(Q_{t+1}+\mathcal{D}_{t+1}\right)\right] \\
\frac{1}{1+r_{t}} & =E_{t}\left[M_{t+1}\right]
\end{aligned}
$$

In equilibrium, the representative agent holds the entire supply of both bonds and equities. The latter is normalized to be one, i.e., $\mathcal{Z}_{t}=1 \quad \forall t$. 
Finally, since the agent has no disutility for labor, she will supply her entire endowment, which we normalized to unity.

Resource Constraint Final output is used for consumption, investment in physical capital, factor input used in the production of patents, and R\&D, as well as government expenditures:

$$
\begin{aligned}
Y_{t} & =C_{t}+I_{t}+N_{t} X_{t}+S_{t}+\Gamma_{t} \\
& =C_{t}+I_{t}+N_{t}^{1-\frac{1}{\nu}} G_{t}+S_{t}+\Gamma_{t}
\end{aligned}
$$

where the last equality exploits the optimality conditions and the term $N_{t}^{1-\frac{1}{\nu}} G_{t}$ captures the costs of patent production. Given that $\nu<1$ reflecting monopolistic competition, it follows that a growing intangible capital stock increases the efficiency of patent production, as the costs fall as $N_{t}$ grows.

Given the resources used in the production of patents, in our economy, GDP is obtained as follows

$$
G D P_{t} \equiv Y_{t}-N_{t} X_{t}
$$

Finally, the tax base is given by taxable profits in both final goods and intangible sectors, so that

$$
\begin{aligned}
\operatorname{tax} \text { base }_{t} & =Y_{t}-W_{t} L_{t}-N_{t} \nu X_{t}+N_{t} \Pi_{t} \\
& =Y_{t}-W_{t} L_{t}-N_{t} X_{t}
\end{aligned}
$$

Stock Market Given our definition as stocks as claims to the net payout of all production sector, in the symmetric equilibrium the aggregate dividend becomes

$$
\mathcal{D}_{t}=D_{t}+\Pi_{t} N_{t}-S_{t}
$$


Defining the stock market value to be the discounted sum of future aggregate dividends, exploiting the optimality conditions, this value can be rewritten as

$$
\mathcal{Q}_{t}=q_{t} K_{t+1}+N_{t}\left(V_{t}-\Pi_{t}\right)+E_{t}\left[\sum_{i=0} M_{t+1+i} V_{t+i+1}\left(N_{t+i+1}-(1-\phi) N_{t+i}\right)\right]
$$

similar to Comin, Gertler, Santacreu (2009). The stock return is defined accordingly. The stock market value thus comprises the current market value of the installed capital stock, reflected in the first term, the market value of currently used patents, reflected in the second term, as well as the market value of patents to be developed in the future, as reflected in the third term. Therefore, in addition to the tangible capital stock, the stock market values intangible capital as well as the option value of future intangibles.

The existence of two capital stocks, namely the stock of physical and intangible capital, respectively, gives rise to a cross-section of stock returns in our model. For empirical purposes, we will associate the returns of innovative firms with the return on intangible capital, while we associate the return on physical capital with low $R \& D$ firms in the data. While clearly not unique, we view this mapping as natural and economically meaningful.

\subsection{Discussion}

The previous paragraphs have outlined a stochastic equilibrium model in which innovation through firms' R\&D drives long-term growth rates. Let us quickly describe how, in the context of the model, government debt and fiscal policy affect innovation and thus growth. Following Kung and Schmid

(2015), it can be shown that under the parameteric restriction $\alpha+\frac{\frac{\xi}{\nu}-\xi}{1-\xi}=1$, which we impose in the following, the model is equivalent to a real business cycle model with a standard neoclassical production function of the form $Y_{t}=Z_{t} K_{t}^{\alpha} L_{t}^{1-\alpha}$ where

$$
Z_{t} \equiv \bar{A}\left(\Omega_{t} N_{t}\right)^{1-\alpha}
$$

is an endogenous productivity process, with $\bar{A} \equiv(\xi \nu)^{\frac{\xi}{(1-\xi)}}>0$. In other words, our model can be seen as a real business cycle model in which productivity is endogenously driven by the accumulation 
of intangible capital via innovation. Taxation thus directly affects growth and its dynamics through its effects on the demand for intangible capital.

Two channels shape the accumulation of intangible capital. First, the final good firm's demand

for patents, $P_{i, t}=\left(K_{t}^{\alpha}\left(\Omega_{t} L_{t}\right)^{1-\alpha}\right)^{1-\xi} \frac{\xi}{\nu}\left[\int_{0}^{N_{t}} X_{i, t}^{\nu} d i\right]^{\frac{\xi}{\nu}-1} \nu X_{i, t}^{\nu-1}$, depends positively on the capital stock, whose accumulation itself is affected by taxation. By slowing down capital accumulation, taxation also depresses innovation and growth. Second, taxation affects the valuation of patents as the value of a patent is given by $V_{i, t}=\left(1-\tau_{t}\right) \Pi_{t}+(1-\phi) E_{t}\left[M_{t+1} V_{i, t+1}\right]$. Higher taxes thus depress patent valuations, which lowers the incentives to engage in innovation, as the value of patents is the payoff to $R \& D$.

To sum up, in our model with stochastic endogenous growth, higher taxes and expectation of an elevated tax burden going forward, depresses firms' incentive to engage innovation, thereby slowing down growth prospects. Since tax rates in our model reflect both the government's expenditures and its indebtedness through its budget constraint, we expect the model to generate predictions on the links between debt, growth and innovation. We examine these predictions quantitatively in the next section.

\section{Quantitative Analysis}

In this section we calibrate our model and explore its ability to rationalize key links between debt, innovation and stock returns in the cross-section and the time series.

The model is calibrated at a quarterly frequency. The empirical moments correspond to the US sample from 1953 to 2014 . We focus on this particular period as R\&D data becomes available only in 1953. The model is solved using second-order perturbation methods.

\subsection{Calibration}

Our baseline model is calibrated at the quarterly frequency under the environment of an average Debt/GDP level of approximately $60 \%$. We target an average annual consumption growth of $2.0 \%$ and average annual consumption volatility of $1.6 \%$. Table 8 summarizes our parameter choices.

The household's subjective discount rate, risk aversion, and the elasticity of inter-temporal 
substitution (EIS) are chosen to align with the average historical level of the risk-free and reproduce a consumption return premium consistent with Lustig, Van Nieuwerburgh and Verdelhan (RFS, 2013). Risk aversion $(\gamma)$ is calibrated to 10, in-line with reasonable upper bounds (Mehra and Prescott, 1985 among others) and EIS $(\psi)$ is set to 1.2, a consistent choice within the set of empirical results in the long-run risk literature.

In order to focus our model on capturing a key dimension of our empirical analysis, notably that the average return premium between the $R \& D$ and physical capital sector is positive, we soften the capital adjustment costs by setting the elasticity of the adjustment cost function $(\zeta)$ to 13.3 . The elasticity of substitution between intermediate goods $(\nu)$ is set to capture the fact that the level of productivity in the final goods sector is increasing. $\alpha$ is set to align with the average capital share. The annualized capital depreciation rate $(\delta)$ is set to $8 \%$.

In the $\mathrm{R} \& \mathrm{D}$ sector, we set the quarterly survival rate $\phi$ of a patent to 0.96 , corresponding to an annual average depreciation rate of $16 \%$, which is in-line with the BEA's annual depreciation rate for $\mathrm{R} \& \mathrm{D}$ capital. The elasticity of new intermediate goods with respect to $\mathrm{R} \& \mathrm{D}(\eta)$ is set to the value consistent with Croce, Nguyen and Schmid (2012). $\chi$ is a scale parameter that is set to match the average overall growth rate of the economy.

The government expenditure process is chosen to produce a ratio of government expenditures to GDP of $11.5 \%$, which is conservative relative to the historical average. Our debt policy rule volatility parameter is set to align with the $19 \%$ historical average annual volatility of debt/GDP. In our decomposition of debt/GDP shocks, we parsimoniously set $A_{z}=-1$ and $A_{\Gamma}=1$ to capture the government expanding its financing in response to a negative technology or a positive government spending shock.

\section{$4.2 \quad$ Findings}

We start by evaluating the overall fit of the model regarding stylized facts about economic growth, cycles and asset returns, and then turn to a more detailed discussion of the cross-sectional and time series links between debt, innovation and returns, motivated by our empirical evidence. 


\subsubsection{Basic Moments}

Table 9 reports basic moments from model simulations, both for quantities and for returns. The table shows results from two specifications, namely one in which we target a realistic average debt to gdp ratio of about $60 \%$ with a volatility of $18 \%$, and another where the average indebtedness is set to zero. These two specifications will be useful in highlighting some of the nonlinearities in our model.

The table shows that the model is qualitatively, and sometimes quantitatively consistent with basic patterns about real aggregates, such as output, consumption and investment, but also innovation and endogenous productivity. Consumption is realistically smooth, with an annual stadard deviation of about $1.6 \%$, which corresponds to the postwar average in the US. As in the data, investment in $R \& D$ is quite a bit more volatile than output, as is physical investment. We note that the model matches the average growth rate of the economy quite well. In our model with innovation driven endogenous growth matching the average growth rate imposes additonal restrictions on the calibration, beyond those in a standard real business cycle model.

Our calibration matches the average debt to gdp ratio, and its volatility, as well as the mean and the dynamics of government expenditures by construction. The corresponding parameter choices, however, imply endogenous dynamics for the tax process, by virtue of the government's budget constraint. Our calibration implies an average tax rate of about 20 percent and a volatility of about 15 percent. While, given the complexity of the tax code, it is hard to empirically identify one representative tax rate on corporate profits, we note that our results on the mean tax rate are on the lower side of the estimates in McGrattan and Prescott (2005), who construct an aggregate tax rate from data on tax receipts. The volatility in our process matches their estimate quite well.

Turning to returns, perhaps not surprisingly, our model does not give a quantitatively realistic account of average excess returns. However, we discipline our calibration by closely matching the excess return on the consumption claim, as empirically measured by Lustig, Van Nieuwerburgh, and Verdelhan (2010). Moreover, and perhaps more importantly for our purposes, the model gives rise to a realistic spread between the excess returns on tangible and intangible capital. In our mapping of intangible capital intensive firms with innovative firms, this implies that firms with higher R\&D intensity earn a positive premium. This fits well with the observed excess returns on 
R\&D in the data. Finally, in line with the long run calibration of the model, we obtain a low and smooth risk free rate.

\subsubsection{Asset Pricing Implications}

We now proceed to examine the cross-sectional and time-series evidence uncovered in our empirical work through the lens of the model. Table 10 starts this investigation by reporting results from joint GMM estimates of factor loadings, and the factor risk premium associated with movements in government debt, from model simulations. We consider a two-asset cross-section, where low R\&D and high R\&D betas correspond to the physical capital and intangible capital returns. The table reports the factor loadings of these two assets and the risk price associated with the debt factor, along with t-stats. Given long simulated samples, we find very high significance with all of the estimates.

We distinguish a few different cases, in order to illuminate the mechanisms at work. First, we can specify $\phi$, the fiscal authorities response to disturbances, to be positive or negative. Given our parameterization, a positive $\phi$ corrsponds to a countercyclical debt policy, in which the government issues debt in response to adverse economic conditions, in an attempt to attenuate the tax burden on corporations in downturns. This can be understood as an attempt to stimulate the economy. While this appears to be a likely realistic scenario we also consider the case with $\phi<0$, in which the government issues debt procyclically, perhaps in an attempt to take advantage of a beneficial bond market environment.

Next, we give the fiscal authority the flexibility to respond to different sources of shocks. These can stem from fundamental innovations in technology, or from innovations to government expenditures. Additonally, we model innovations in the debt policy unrelated to the former, which is what we label pure debt policy shocks. We think of these shocks as arising from the budget negotation

process, for example, or from shifts in the political composition of the administration . In this sense, they represent pure political uncertainty.

We take the specification with a countercyclical debt policy, and with productivity, expenditure and policy shocks, as our benchmark model. We first observe that in our benchmark model, reported under the label 'All', we rationalize the cross-sectional evidence qualitatively well. We 
find positive and significant factor loadings of our simulated test assets on the government debt factor, along with a positive factor risk premium. Moreover, there is a substantial spread in the factor loadings between high and low R\&D portfolios, with the more innovative asset displaying a significantly higher loading. In other words, innovative firms in the model earn a positive premium for their exposure to movements in government debt. Moving from the zero average debt to the high average debt to gdp case with debt with a mean of around $60 \%$, the factor risk premium rises substantially. Since the debt to gdp ratio in the model is voatile and moves wit economic conditions, this indicates that the model generates substantial movements in the conditional factor risk premium.

To highlight the mechanism underlying our findings, we find it instructive to consider the case without pure debt policy shocks. That is, in this case, we shut down political uncertainty altogether. Remarkably, as the table shows, the estimated factor loadings and the factor risk premium are now estimated to be significantly negative in the case with a countercyclical debt policy. In contrast, the estimates are all positive in case of procyclical debt policy. We note that the return spreads between high and low innovative intensity assets are invariably positive.

Intuitively, the negative factor risk premium in case of a countercyclical debt policy is not surprising. In a world driven by productivity and government expenditure shocks, government debt will be high precisely when productivity is low, and thus asset returns are low. The factor loadings are thus negative, but these are assets performing badly in bad times. This requires a risk premium, rendering the factor risk premium negative. This is precisely what happens in the case abstracting from debt policy shocks, where the link between productivity and government debt is especially tight. Because of this tight link, the sign of the factor risk price flips once debt policy becomes procyclical.

Accounting for debt policy shocks break this tight link, allowing the estimated price of risk to be positive, as in the data. Intuitively, modeling political uncertainty in the government budget process allows for variation in the debt to gdp ratio independent from productivity shocks. More formally, our model is a conditional three-factor model, in which innovative firms provide insurance against debt policy shocks, but relatively less so when debt is really high, that is in really bad times. As we noted above, the conditional factor risk premium is increasing in government indebtedness. The 
result is, after conditionig down, unconditionally positive factor loadings and factor risk premium, as we observe in the data. Through the lens of the model, these results highlight the role of fiscal uncertainty in the form of pure political uncertainty, in shaping the empirical relationships.

Our cross-sectional findings in the model empasized the importance of movements in conditional factor risk premia in response to swings in government debt. This suggests that risk premia in the model should be predictable by means of the debt to gdp ratio. We next present evidence to this effect. Table 11 shows the results of running predictive regressions of future stock returns at various horizons on the current debt to gdp ratio, and verifies that this variable significantly predicts higher returns going forward. This is in line with notion that times of high government debt correspond to bad, or high marginal utility states, for the household in the model. Given the evidence given earlier that the conditional risk price on government debt is increasing in debt, the sign of the predictive coefficient is perhaps intuitive and not surprising. However, also in line with the evidence, the model rationalizes well the observation that the spread between high and low R\&D firms is increasing in indebtedness. This finding highlights the importance of accounting for conditioning information in nonlinear asset pricing models such as ours.

\section{Conclusion}

We present novel empirical evidence that government debt, as measured for example by the debt to gdp ratio, is a risk factor priced in stock markets. In the cross-section, we find that portfolios of stocks exhibiting higher exposure to movements in government debt earn higher average returns, even after controlling for standard risk factors. In the time series, the debt-to-gdp ratio significantly predicts higher future aggregate stock returns at longer horizons, even when controlling for standard predictors such as price-dividend ratios and market volatility.

Critically, we document that innovative firms earn a substantial premium for their exposure to movements in government debt. Government debt also predicts higher returns on innovative stocks going forward, so that this premium rises with the debt to gdp ratio. We show that rises in the cost of capital for innovation-intensive firms associated with elevated government debt bring about declines in R\&D activity and economic growth. While the literature has discussed numerous 
channels through which high government indebtedness could harm future economic growth, our findings identify a novel risk based mechanism that works through innovative firms' cost of capital. Our results thus corroborate common concerns that government debt may dampen future growth prospects.

We interpret our empirical results in the context of an equilibrium production ecomomy, in which endogenous innovation drives long-term growth. Corporate investment and innovation depend on the government fiscal policy stance, which resorts to taxation to ensure budget balance. Unexpected movements in the government's debt policy give rise to a risk factor priced in the cross-section of returns. We find that in the model agents require a premium to hold innovative stocks due to this exposure. The model thus highlights the role of political and fiscal uncertainty underlying our empirical evidence. 


\section{$6 \quad$ References}

Ai, Hengjie, Massimiliano Croce, and Kai Li, 2013, Towards a quantitative equilibrium model of intangible capital, Review of Financial Studies 26(2).

Alvarez, Fernando, and Urban Jermann, 2005, Using asset prices to measure the persistence of the marginal utility of wealth, Econometrica 73, 1977-2016.

Backus, David, Mikhail Chernov, and Stanley Zin, 2012, Sources of entropy in representative agent models, forthcoming Journal of Finance.

Backus, David, Bryan Routledge, and Stanley Zin, 2007, Asset prices in business cycle analysis, Working paper, New York University.

Backus, David, Bryan Routledge, and Stanley Zin, 2010, Cyclical component of U.S. asset returns, Working paper, New York University.

Bansal, Ravi, Dana Kiku, and Amir Yaron, 2013, Risks for the long run: Estimation with time aggregation, Working paper, Duke University.

Bansal, Ravi, and Amir Yaron, 2004, Risks for the long run: A potential resolution of asset pricing puzzles, Journal of Finance 59, 1639-1672.

Boldrin, Michele, Lawrence Christiano, and Jonas Fisher, 2001, Habit persistence, asset returns and the business cycle, American Economic Review 91, 149-166.

Campanale, Claudio, Rui Castro, and Gian Luca Clementi, 2008, Asset pricing in a production economy with Chew-Dekel preferences, Review of Economic Dynamics 13, 379-402.

Carlson, Murray, Adlai Fisher, and Ron Giammarino, 2004, Corporate investment and asset price dynamics: Implications for the cross-section of returns, Journal of Finance 59, 2577-2603.

Christiano, Lawrence, and Terry Fitzgerald, 2003, The band-pass filter, International Economic Review 44, 435-465.

Cogley, Tim, and James Nason, 1995, Output dynamics in real business cycle models, American Economic Review 85, 492-511. 
Comin, Diego, and Mark Gertler, 2006, Medium term business cycles, American Economic Review $96,523-551$.

Comin, Diego, Mark Gertler, and Ana Maria Santacreu, 2009, Technology innovation and diffusion as sources of output and asset price fluctuations, Working paper, Harvard University.

Croce, Massimiliano, 2012, Long-run productivity risk: A new hope for production-based asset pricing, Working paper, forthcoming Journal of Monetary Economics.

Dixit, Avinash, and Joseph Stiglitz, 1977, Monopolistic competition and optimum product diversity, American Economic Review 67, 297-308.

Ethier, Wilfried, 1982, National and international returns to scale in the modern theory of international trade, American Economic Review 72, 389-405.

Favilukis, Jack, and Xiaoji Lin, 2013a, Long run productivity risk and aggregate investment, forthcoming Journal of Monetary Economics.

Favilukis, Jack, and Xiaoji Lin, 2013b, Wage rigidity: A quantitative solution to several asset pricing puzzles, Working paper, London School of Economics.

Fernandez-Villaverde, Jesus, Ralph Koijen, Juan Rubio-Ramirez, and Jules van Binsbergen, 2012, The term structure of interest rates in a DSGE model with recursive preferences, Journal of Monetary Economics 59, 634-648.

Gala, Vito, 2010, Irreversible investment and the cross-section of stock returns in general equilibrium, Working paper, London Business School.

Garleanu, Nicolae, Leonid Kogan, and Stavros Panageas, 2012, The demographics of innovation and asset returns, Journal of Financial Economics 105, 491-510.

Garleanu, Nicolae, Stavros Panageas, and Jianfeng Yu, 2012, Technological growth and asset pricing, Journal of Finance 67, 1265-1292.

Gomes, João F., Leonid Kogan, and Motohiro Yogo, 2009, Durability of output and expected stock returns, Journal of Political Economy 117, 941-986. 
Gomes, João F., Leonid Kogan, and Lu Zhang, 2003, Equilibrium cross-section of returns, Journal of Political Economy, 111, 693-731.

Gordon, Robert J., 2010, Revisiting U.S. productivity growth over the past century with a view of the future, Working paper, Northwestern University.

Gourio, Francois, 2012, Disaster risk and business cycles, American Economic Review 102, 27342766 .

Gourio, Francois, 2013, Credit risk and disaster risk, American Economic Journal: Macroeconomics 5, 1-34.

Griliches, Zvi, 1990, Patent statistics as economic indicators: A survey, Journal of Economic Literature.

Grossman, Gene, and Elhanan Helpman, 1991, Innovation and Growth in the Global Economy, MIT Press.

Helpman, Elhanan, 1998, General Purpose Technologies and Economic Growth, MIT Press.

Jermann, Urban, 1998, Asset pricing in production economies, Journal of Monetary Economics $41,257-275$.

Jermann, Urban, and Vincenzo Quadrini, 2007, Stock market boom and the productivity gains of the 1990s, Journal of Monetary Economics 54, 413-432.

Jovanovic, Boyan, and Peter Rousseau, 2006, General purpose technologies, Handbook of Economic Growth.

Kaltenbrunner, Georg, and Lars Lochstoer, 2010, Long run risk through consumption smoothing, Review of Financial Studies 23, 3190-3224.

Kogan, Leonid, and Dimitris Papanikolaou, 2010, Growth opportunities and technology shocks, American Economic Review 100, 532-536.

Kogan, Leonid, Dimitris Papanikolaou, and Noah Stoffman, 2012, Technological innovation: Winners and losers, Working paper, MIT. 
Kuehn, Lars-Alexander, 2008, Asset pricing implications of real investment commitment, Working paper, Carnegie Mellon University.

Kung, Howard, 2013, A macroeconomic foundation for the equilibrium term structure of interest rates, forthcoming Journal of Financial Economics.

Lin, Xiaoji, 2012, Endogenous technological progress and the cross-section of stock returns, Journal of Financial Economics 103, 411-428.

Papanikolaou, Dimitris, 2011, Investment shocks and asset prices, Journal of Political Economy 119, 639-685.

Pastor, Lubos, and Pietro Veronesi, 2009, Technological revolutions and stock prices, American Economic Review 99, 1451-1483.

Romer, Paul, 1990, Endogenous technological change, Journal of Political Economy 98, 71-102.

Tallarini, Thomas, 2000, Risk-sensitive real business cycles, Journal of Monetary Economics 45, $507-532$.

Zhang, Lu, 2005, The value premium, Journal of Finance 60, 67-103. 
Table 1: This table shows results from our GMM estimation of a linear factor model with Debt/GDP. We present both the first stage portfolio $\beta$ exposures, the factor mean $\mu$, and the factor risk premia $\lambda$ below. We use return residuals from projecting portfolio returns onto the three Fama-French factors in our estimation. Results are presented as [estimate; standard error; t-stat], where standard errors are computed from Newey-West (1987).

\begin{tabular}{|c|c|}
\hline \multicolumn{2}{|c|}{$\beta$ Factor Loadings } \\
\hline Portfolios & Debt/GDP \\
\hline \multirow[t]{3}{*}{ Low } & 0.026 \\
\hline & $(0.013)$ \\
\hline & 2.031 \\
\hline \multirow[t]{3}{*}{ Middle } & 0.016 \\
\hline & $(0.010)$ \\
\hline & 1.567 \\
\hline \multirow[t]{3}{*}{ High } & 0.073 \\
\hline & $(0.024)$ \\
\hline & 3.042 \\
\hline \multirow{3}{*}{ HML } & 0.046 \\
\hline & $(0.020)$ \\
\hline & 2.315 \\
\hline \multirow[t]{3}{*}{ Market } & 0.036 \\
\hline & $(0.013)$ \\
\hline & 2.813 \\
\hline \multicolumn{2}{|l|}{ Factor Means } \\
\hline \multirow[t]{3}{*}{$\mu$} & 0.526 \\
\hline & $(0.019)$ \\
\hline & 27.989 \\
\hline \multicolumn{2}{|l|}{ Factor Risk Premia } \\
\hline$\lambda$ & 0.3063 \\
\hline & $\begin{array}{r}(0.109) \\
2.800\end{array}$ \\
\hline
\end{tabular}


Table 2: This table shows results from our GMM estimation of a linear factor model with three Fama-French factors and Debt/GDP. We present both the first stage portfolio $\beta$ exposures, the factor mean $\mu$, and the factor risk premia $\lambda$ below. We use both our R\&D intensity sorted portfolios as well as the 5 industry portfolios from Kenneth French's website in estimation. Results are presented as [estimate; standard error; t-stat], where standard errors are computed from Newey-West (1987).

\begin{tabular}{|c|c|c|c|c|}
\hline \multirow[b]{2}{*}{ Portfolios } & \multicolumn{4}{|c|}{$\beta$ Factor Loadings } \\
\hline & $\mathrm{Rm}-\mathrm{Rf}$ & SMB & HML & Debt/GDP \\
\hline \multirow{6}{*}{ Middle } & 0.830 & 0.937 & 0.401 & 0.044 \\
\hline & $(0.079)$ & $(0.115)$ & $(0.076)$ & $(0.022)$ \\
\hline & 10.492 & 8.175 & 5.285 & 2.028 \\
\hline & 0.898 & 0.659 & 0.265 & 0.021 \\
\hline & $(0.064)$ & $(0.104)$ & $(0.082)$ & $(0.017)$ \\
\hline & 13.984 & 6.332 & 3.244 & 1.241 \\
\hline \multirow[t]{3}{*}{ High } & 0.997 & 0.988 & -0.125 & 0.091 \\
\hline & $(0.079)$ & $(0.139)$ & $(0.136)$ & $(0.029)$ \\
\hline & 12.673 & 7.130 & -0.921 & 3.110 \\
\hline \multirow[t]{3}{*}{ HML } & 0.167 & 0.051 & -0.526 & 0.047 \\
\hline & $(0.096)$ & $(0.125)$ & $(0.156)$ & $(0.023)$ \\
\hline & 1.740 & 0.404 & -3.370 & 2.066 \\
\hline \multirow[t]{3}{*}{ Market } & 0.802 & 0.650 & 0.183 & 0.039 \\
\hline & $(0.064)$ & $(0.102)$ & $(0.076)$ & $(0.018)$ \\
\hline & 12.613 & 6.354 & 2.403 & 2.193 \\
\hline \multirow[t]{3}{*}{ Cnsmr } & 0.311 & 0.050 & 0.032 & -0.004 \\
\hline & $(0.016)$ & $(0.021)$ & $(0.024)$ & $(0.003)$ \\
\hline & 19.463 & 2.413 & 1.336 & -1.571 \\
\hline \multirow[t]{3}{*}{ Manuf } & 0.299 & -0.046 & 0.037 & -0.011 \\
\hline & $(0.012)$ & $(0.016)$ & $(0.019)$ & $(0.004)$ \\
\hline & 25.092 & -2.882 & 1.984 & -3.029 \\
\hline \multirow[t]{3}{*}{ HiTec } & 0.353 & 0.000 & -0.070 & -0.008 \\
\hline & $(0.020)$ & $(0.023)$ & $(0.023)$ & $(0.005)$ \\
\hline & 17.660 & -0.009 & -3.084 & -1.756 \\
\hline \multirow[t]{2}{*}{ Hlth } & 0.299 & -0.103 & -0.070 & -0.009 \\
\hline & $(0.018)$ & $(0.024)$ & $(0.031)$ & $(0.003)$ \\
\hline & 16.261 & -4.400 & -2.283 & -2.529 \\
\hline \multirow[t]{3}{*}{ Other } & 0.383 & 0.038 & 0.095 & -0.015 \\
\hline & $(0.012)$ & $(0.020)$ & $(0.018)$ & $(0.004)$ \\
\hline & 33.043 & 1.925 & 5.324 & -4.143 \\
\hline \multicolumn{5}{|l|}{ Factor Means } \\
\hline \multirow[t]{3}{*}{$\mu$} & 0.016 & 0.009 & 0.009 & 0.510 \\
\hline & $(0.006)$ & $(0.004)$ & $(0.005)$ & $(0.023)$ \\
\hline & 2.500 & 2.244 & 1.809 & 22.454 \\
\hline \multicolumn{5}{|l|}{ Factor Risk Premia } \\
\hline \multirow[t]{3}{*}{$\lambda$} & 0.040 & -0.037 & 0.027 & 0.512 \\
\hline & $(0.010)$ & $(0.029)$ & $(0.033)$ & $(0.284)$ \\
\hline & 3.856 & -1.298 & 0.814 & 1.804 \\
\hline \multicolumn{5}{|c|}{30} \\
\hline
\end{tabular}


Table 3: This table shows results from our GMM estimation of a linear factor model with three Fama-French factors and Debt/GDP. We present both the first stage portfolio $\beta$ exposures, the factor mean $\mu$, and the factor risk premia $\lambda$ below. We use both our R\&D intensity sorted portfolios as well as the 48 industry portfolios from Kenneth French's website in estimation. We only present $\beta$ exposures for our R\&D sorted portfolios. Results are presented as [estimate; standard error; t-stat], where standard errors are computed from Newey-West (1987). GMM with R\&D and 48 Fama-French Industry Portfolios

\begin{tabular}{|c|c|c|c|c|}
\hline \multirow[b]{2}{*}{ Portfolios } & \multicolumn{4}{|c|}{$\beta$ Factor Loadings } \\
\hline & Rm-Rf & SMB & HML & Debt/GDP \\
\hline \multirow[t]{3}{*}{ Low } & 0.877 & 0.873 & 0.421 & 0.045 \\
\hline & $(0.081)$ & $(0.269)$ & $(0.027)$ & $(0.022)$ \\
\hline & 10.882 & 3.252 & 15.444 & 2.006 \\
\hline \multirow[t]{3}{*}{ Middle } & 0.877 & 0.691 & 0.213 & 0.026 \\
\hline & $(0.093)$ & $(0.036)$ & $(0.078)$ & $(0.016)$ \\
\hline & 9.469 & 19.311 & 2.718 & 1.692 \\
\hline \multirow[t]{3}{*}{ High } & 1.037 & 0.904 & -0.098 & 0.089 \\
\hline & $(0.043)$ & $(0.061)$ & $(0.142)$ & $(0.029)$ \\
\hline & 23.853 & 14.788 & -0.693 & 3.089 \\
\hline \multirow[t]{3}{*}{ HML } & 0.154 & 0.074 & -0.538 & 0.048 \\
\hline & $(0.069)$ & $(0.227)$ & $(0.184)$ & $(0.017)$ \\
\hline & 2.218 & 0.324 & -2.919 & 2.804 \\
\hline \multirow[t]{3}{*}{ Market } & 0.788 & 0.670 & 0.147 & 0.046 \\
\hline & -0.099 & -0.018 & -0.025 & -0.018 \\
\hline & 1.547 & 3.997 & -21.731 & 2.702 \\
\hline \multicolumn{5}{|l|}{ Factor Means } \\
\hline \multirow[t]{3}{*}{$\mu$} & 0.016 & 0.009 & 0.009 & 0.521 \\
\hline & $(0.007)$ & $(0.009)$ & $(0.003)$ & $(0.043)$ \\
\hline & 2.431 & 1.047 & 3.560 & 12.042 \\
\hline \multicolumn{5}{|l|}{ Factor Risk Premia } \\
\hline \multirow[t]{3}{*}{$\lambda$} & 0.048 & -0.044 & 0.020 & 0.412 \\
\hline & $(0.005)$ & $(0.005)$ & $(0.008)$ & $(0.140)$ \\
\hline & 9.373 & -8.840 & 2.558 & 2.951 \\
\hline
\end{tabular}


Table 4: This table shows results from predictive regressions of R\&D returns for portfolios formed based on R\&D intensity on price/dividend, Debt/GDP, and market volatility. Data is from 2Q1966-4Q2013 at the quarterly frequency. The timing of the predictive regressions is based on cumulative future returns over quarters. t-statistics are based on Newey-West (1987) standard errors.

\begin{tabular}{|c|c|c|c|c|c|c|c|c|c|c|}
\hline & \multicolumn{5}{|c|}{ Estimates } & \multicolumn{5}{|c|}{ t-stats } \\
\hline & $\mathrm{T}+1$ & $\mathrm{~T}+2$ & $\mathrm{~T}+4$ & $\mathrm{~T}+8$ & $\mathrm{~T}+20$ & $\mathrm{~T}+1$ & $\mathrm{~T}+2$ & $\mathrm{~T}+4$ & $\mathrm{~T}+8$ & $\mathrm{~T}+20$ \\
\hline & \multicolumn{10}{|c|}{$P / D$ Coefficient } \\
\hline Low R\&D & -0.0003 & -0.0006 & -0.0011 & -0.0021 & -0.0056 & -0.4029 & -0.6627 & -0.8613 & -1.3763 & -2.7515 \\
\hline Port. 2 & -0.0005 & -0.0010 & -0.0020 & -0.0036 & -0.0070 & -0.5902 & -0.7488 & -1.0311 & -1.3325 & -2.0553 \\
\hline Port. 3 & -0.0003 & -0.0008 & -0.0018 & -0.0041 & -0.0082 & -0.2998 & -0.4871 & -0.7159 & -1.0812 & -2.4108 \\
\hline Port. 4 & 0.0015 & 0.0021 & 0.0035 & 0.0059 & 0.0116 & 1.9250 & 1.9073 & 2.0173 & 2.6023 & 4.3712 \\
\hline Port. 5 & -0.0009 & -0.0015 & -0.0028 & -0.0049 & -0.0086 & -1.1437 & -1.3940 & -1.7611 & -2.5660 & -3.0361 \\
\hline Port. 6 & -0.0003 & -0.0007 & -0.0014 & -0.0027 & -0.0051 & -0.3796 & -0.6958 & -1.0422 & -1.7142 & -2.2672 \\
\hline Port. 7 & -0.0007 & -0.0013 & -0.0025 & -0.0048 & -0.0101 & -0.6748 & -0.8645 & -1.1691 & -1.9199 & -4.2494 \\
\hline Port. 8 & -0.0007 & -0.0013 & -0.0025 & -0.0047 & -0.0089 & -0.6258 & -0.7450 & -1.0458 & -1.4967 & -2.6834 \\
\hline Port. 9 & -0.0020 & -0.0033 & -0.0056 & -0.0105 & -0.0216 & -1.7589 & -2.0812 & -2.4992 & -3.4284 & -6.0488 \\
\hline High R\&D & 0.0007 & 0.0007 & 0.0007 & 0.0008 & 0.0016 & 0.5126 & 0.3745 & 0.2556 & 0.2242 & 0.5114 \\
\hline HML & 0.0009 & 0.0013 & 0.0018 & 0.0030 & 0.0074 & 0.7140 & 0.6897 & 0.6872 & 0.9385 & 2.2503 \\
\hline Mrkt. & -0.0002 & -0.0005 & -0.0012 & -0.0025 & -0.0041 & -0.2139 & -0.5123 & -0.8166 & -1.3195 & -3.1938 \\
\hline & \multicolumn{10}{|c|}{ Debt/GDP Coefficient } \\
\hline Low R\&D & 1.2692 & 1.2172 & 2.0877 & 1.6312 & 2.0968 & 1.9585 & 1.6011 & 1.6577 & 0.9165 & 0.7959 \\
\hline Port. 2 & 0.8653 & 0.9959 & 0.6982 & 0.0964 & 0.4016 & 0.9920 & 0.8236 & 0.4160 & 0.0358 & 0.1096 \\
\hline Port. 3 & 1.1920 & 1.5177 & 2.2592 & 2.6429 & 8.5606 & 1.4202 & 1.4114 & 1.5217 & 1.2618 & 3.2465 \\
\hline Port. 4 & 1.3815 & 1.3517 & 2.8594 & 4.3750 & 10.5225 & 1.7570 & 1.6181 & 2.1115 & 2.0856 & 3.5277 \\
\hline Port. 5 & 1.8266 & 2.4297 & 3.8455 & 4.8552 & 7.6731 & 2.7175 & 2.9442 & 3.3403 & 3.0594 & 3.5944 \\
\hline Port. 6 & 2.2797 & 2.8085 & 4.9070 & 6.1076 & 8.8291 & 3.0368 & 3.2722 & 4.5716 & 4.2501 & 3.8129 \\
\hline Port. 7 & 0.9026 & 1.0021 & 1.8952 & 1.5888 & 2.1497 & 1.2153 & 1.2847 & 1.6715 & 1.0809 & 1.1128 \\
\hline Port. 8 & 1.1001 & 1.8134 & 3.0348 & 4.3017 & 7.2286 & 1.0057 & 1.6427 & 1.7965 & 2.1325 & 3.2924 \\
\hline Port. 9 & 1.3892 & 0.9734 & 2.9665 & 1.3743 & 0.7634 & 1.4512 & 0.8738 & 1.6743 & 0.4629 & 0.1869 \\
\hline High R\&D & 2.6980 & 3.3672 & 5.8222 & 7.3119 & 13.8965 & 2.7475 & 3.1996 & 4.1426 & 4.0982 & 6.6430 \\
\hline HML & 1.4695 & 2.1821 & 3.8555 & 5.8642 & 12.0895 & 2.1014 & 2.3207 & 3.1696 & 3.6105 & 4.7933 \\
\hline \multirow[t]{2}{*}{ Mrkt. } & 1.3294 & 1.6325 & 2.9628 & 3.5359 & 6.1972 & 1.7998 & 1.9264 & 2.7559 & 3.2844 & 5.5552 \\
\hline & \multicolumn{10}{|c|}{ Market Volatility Coefficient } \\
\hline Low R\&D & 0.3066 & 1.3160 & 1.8498 & 2.5051 & 2.5411 & 0.3793 & 1.1180 & 1.3534 & 1.5624 & 1.7590 \\
\hline Port. 2 & -0.0307 & 0.9072 & 1.4865 & 2.7997 & 3.0923 & -0.0437 & 0.8279 & 1.0963 & 1.6284 & 1.7283 \\
\hline Port. 3 & -0.9108 & -1.0105 & -0.6364 & 0.0116 & 0.6846 & -1.7257 & -1.7605 & -0.7980 & 0.0088 & 0.4175 \\
\hline Port. 4 & -0.2264 & 0.4170 & 0.5522 & 0.9548 & 1.4334 & -0.3753 & 0.6100 & 0.5637 & 0.7203 & 0.8897 \\
\hline Port. 5 & -0.6770 & -0.1444 & 0.1598 & 1.0845 & 1.9392 & -1.1703 & -0.1835 & 0.1604 & 0.8326 & 1.5938 \\
\hline Port. 6 & -0.5968 & 0.2381 & 0.5900 & 1.0338 & 1.0877 & -0.9112 & 0.4259 & 0.7909 & 0.8405 & 0.9002 \\
\hline Port. 7 & -0.0899 & 0.7033 & 0.8873 & 1.4730 & 0.9496 & -0.1825 & 1.1084 & 1.2197 & 1.6648 & 0.7450 \\
\hline Port. 8 & -0.9166 & -0.7401 & -0.0585 & 0.3688 & 0.5878 & -1.8979 & -1.6483 & -0.0896 & 0.3425 & 0.5097 \\
\hline Port. 9 & -0.3346 & 0.8913 & 1.0216 & 3.0087 & 3.5691 & -0.4372 & 0.8194 & 0.6435 & 1.1108 & 1.5759 \\
\hline High R\&D & -0.1879 & 0.4983 & 0.5928 & 1.0758 & 0.4100 & -0.3112 & 0.7568 & 0.6041 & 0.8409 & 0.3021 \\
\hline HML & -0.4934 & -0.7981 & -1.2593 & -1.3938 & -2.1061 & -1.2405 & -1.1116 & -1.5256 & -1.5626 & -1.5214 \\
\hline \multirow[t]{2}{*}{ Mrkt. } & -1.0083 & -0.4175 & -0.3100 & 0.2230 & -0.1298 & -2.0857 & -0.8544 & -0.5484 & 0.3666 & -0.1875 \\
\hline & & & $R^{2}$ & & & & & & & \\
\hline Low R\&D & 0.0288 & 0.0663 & 0.1021 & 0.0920 & 0.1241 & & & & & \\
\hline Port. 2 & 0.0122 & 0.0340 & 0.0434 & 0.0672 & 0.0809 & & & & & \\
\hline Port. 3 & 0.0201 & 0.0229 & 0.0332 & 0.0570 & 0.2082 & & & & & \\
\hline Port. 4 & 0.0452 & 0.0571 & 0.0956 & 0.1325 & 0.2365 & & & & & \\
\hline Port. 5 & 0.0595 & 0.0827 & 0.1478 & 0.2203 & 0.2938 & & & & & \\
\hline Port. 6 & 0.0691 & 0.0946 & 0.1820 & 0.2120 & 0.2368 & & & & & \\
\hline Port. 7 & 0.0160 & 0.0372 & 0.0753 & 0.1251 & 0.2486 & & & & & \\
\hline Port. 8 & 0.0256 & 0.0358 & 0.0682 & 0.1107 & 0.2636 & & & & & \\
\hline Port. 9 & 0.0386 & 0.0667 & 0.1241 & 0.1904 & 0.3390 & & & & & \\
\hline High R\&D & 0.0592 & 0.0781 & 0.1322 & 0.1386 & 0.1972 & & & & & \\
\hline HML & 0.0326 & 0.0440 & 0.0785 & 0.1181 & 0.1983 & & & & & \\
\hline Mrkt. & 0.0503 & 0.0392 & 0.0930 & 0.1293 & 0.2322 & & & & & \\
\hline
\end{tabular}


Table 5: This table shows results from univariate predictive regressions of R\&D returns for portfolios formed based on R\&D intensity on price/dividend, Debt/GDP, and market volatility, respectively. Data is from 2Q1966-4Q2013 at the quarterly frequency. The timing of the predictive regressions is based on cumulative future returns over quarters. t-statistics are based on Newey-West (1987) standard errors.

\begin{tabular}{|c|c|c|c|c|c|c|c|c|c|c|}
\hline & \multicolumn{5}{|c|}{ Estimates } & \multicolumn{5}{|c|}{ t-stats } \\
\hline & $\mathrm{T}+1$ & $\mathrm{~T}+2$ & $\mathrm{~T}+4$ & $\mathrm{~T}+8$ & $\mathrm{~T}+20$ & $\mathrm{~T}+1$ & $\mathrm{~T}+2$ & $\mathrm{~T}+4$ & $\mathrm{~T}+8$ & $\mathrm{~T}+20$ \\
\hline & \multicolumn{10}{|c|}{$P / D$ Coefficient } \\
\hline Low R\&D & -0.0005 & -0.0009 & -0.0016 & -0.0026 & -0.0062 & -0.7389 & -0.9455 & -1.2263 & -1.6965 & -3.1271 \\
\hline Port. 2 & -0.0007 & -0.0012 & -0.0022 & -0.0038 & -0.0073 & -0.7856 & -0.9744 & -1.1998 & -1.4446 & -2.3092 \\
\hline Port. 3 & -0.0005 & -0.0010 & -0.0022 & -0.0046 & -0.0099 & -0.4284 & -0.6141 & -0.8626 & -1.1902 & -2.6063 \\
\hline Port. 4 & 0.0013 & 0.0019 & 0.0030 & 0.0050 & 0.0095 & 1.7194 & 1.7300 & 1.8477 & 2.4349 & 3.4649 \\
\hline Port. 5 & -0.0012 & -0.0019 & -0.0035 & -0.0058 & -0.0102 & -1.4416 & -1.7320 & -2.1667 & -2.9783 & -3.4999 \\
\hline Port. 6 & -0.0006 & -0.0011 & -0.0022 & -0.0038 & -0.0069 & -0.8742 & -1.1937 & -1.6733 & -2.3027 & -2.7806 \\
\hline Port. 7 & -0.0009 & -0.0015 & -0.0029 & -0.0052 & -0.0106 & -0.8439 & -1.0468 & -1.3912 & -2.0606 & -4.5631 \\
\hline Port. 8 & -0.0009 & -0.0015 & -0.0030 & -0.0055 & -0.0103 & -0.7264 & -0.9013 & -1.2578 & -1.7155 & -2.8702 \\
\hline Port. 9 & -0.0022 & -0.0035 & -0.0062 & -0.0109 & -0.0219 & -2.0026 & -2.3077 & -2.7874 & -3.6583 & -6.7204 \\
\hline High R\&D & 0.0002 & 0.0001 & -0.0003 & -0.0006 & -0.0011 & 0.1703 & 0.0506 & -0.1264 & -0.1532 & -0.2798 \\
\hline HML & 0.0007 & 0.0010 & 0.0012 & 0.0021 & 0.0052 & 0.5492 & 0.5170 & 0.4604 & 0.5953 & 1.3292 \\
\hline \multirow[t]{2}{*}{ Mrkt. } & -0.0003 & -0.0008 & -0.0017 & -0.0032 & -0.0052 & -0.4173 & -0.7485 & -1.1242 & -1.5422 & -3.5080 \\
\hline & \multicolumn{10}{|c|}{ Debt/GDP Coefficient } \\
\hline Low R\&D & 1.4422 & 1.8689 & 3.0470 & 3.0492 & 4.2469 & 1.8665 & 2.4968 & 2.8200 & 2.2108 & 1.8510 \\
\hline Port. 2 & 0.9391 & 1.5373 & 1.6438 & 1.8834 & 3.0566 & 0.9606 & 1.38 & 1.1517 & 0.8303 & 0.9896 \\
\hline Port. 3 & 0.8596 & 1.2190 & 2.2781 & 3.3107 & 10.4452 & 0.8966 & 1.0566 & 1.4814 & 1.4943 & 3.7626 \\
\hline Port. 4 & 1.0391 & 1.1884 & 2.5468 & 3.8390 & 8.8585 & 1.1991 & 1.4573 & 2.1179 & 2.1746 & 3.0980 \\
\hline Port. 5 & 1.6838 & 2.6121 & 4.3532 & 6.1037 & 10.1559 & 1.9165 & 2.8076 & 3.9203 & 4.5095 & 5.0133 \\
\hline Port. 6 & 2.0668 & 3.0125 & 5.3701 & 6.9899 & 10.2758 & 2.2533 & 3.5090 & 5.2559 & 5.7465 & 4.8779 \\
\hline Port. 7 & 0.9794 & 1.5059 & 2.6656 & 2.9926 & 4.5105 & 1.3301 & 2.0220 & 2.5588 & 1.9687 & 1.9979 \\
\hline Port. 8 & 0.8280 & 1.6976 & 3.3996 & 5.2239 & 9.2046 & 0.7714 & 1.5166 & 2.0386 & 2.5974 & 3.9124 \\
\hline Port. 9 & 1.5606 & 1.8727 & 4.2859 & 4.3587 & 6.4445 & 1.4085 & 1.7248 & 2.3276 & 1.7285 & 1.6311 \\
\hline High R\&D & 2.5101 & 3.4674 & 5.9665 & 7.6495 & 13.7483 & 2.4766 & 3.1566 & 4.1365 & 4.2637 & 6.8605 \\
\hline HML & 1.1111 & 1.6426 & 3.0387 & 4.7849 & 9.7682 & 1.5922 & 1.7558 & 2.4645 & 2.8235 & 3.8909 \\
\hline \multirow[t]{2}{*}{ Mrkt. } & 0.9258 & 1.5411 & 3.0238 & 4.0419 & 6.9342 & 0.9734 & 1.6493 & 2.8875 & 3.5505 & 5.9297 \\
\hline & \multicolumn{10}{|c|}{ Market Volatility Coefficient } \\
\hline Low R\&D & 0.6046 & 1.6114 & 2.3577 & 2.9452 & 3.1407 & 0.7698 & 1.3979 & 1.8554 & 1.9909 & 2.3431 \\
\hline Port. 2 & 0.1859 & 1.1673 & 1.7138 & 2.9417 & 3.3836 & 0.2561 & 1.0622 & 1.2732 & 1.7453 & 1.8223 \\
\hline Port. 3 & -0.6276 & -0.6393 & -0.0646 & 0.7465 & 2.6972 & -1.3423 & -1.2223 & -0.0871 & 0.6262 & 2.2661 \\
\hline Port. 4 & 0.0299 & 0.6433 & 1.072 & 1.7527 & 3.2626 & 0.0534 & 1.0718 & 1.462 & 2.0144 & 3.0428 \\
\hline Port. 5 & -0.2287 & 0.4583 & 1.1216 & 2.3456 & 3.7799 & -0.4414 & 0.6664 & 1.3642 & 2.3046 & 3.9164 \\
\hline Port. 6 & -0.07 & 0.8938 & 1.7395 & 2.5082 & 3.0633 & -0.1238 & 1.9146 & 2.8052 & 2.637 & 3.0382 \\
\hline Port. 7 & 0.1417 & 0.976 & 1.401 & 1.9914 & 1.6934 & 0.3072 & 1.5747 & 2.0587 & 2.5282 & 1.1861 \\
\hline Port. 8 & -0.6396 & -0.2867 & 0.7101 & 1.5005 & 2.3453 & -1.4992 & -0.5874 & 1.1584 & 1.6022 & 2.1786 \\
\hline Port. 9 & 0.0536 & 1.2299 & 1.8858 & 3.6673 & 4.3664 & 0.0705 & 1.0662 & 1.1651 & 1.3436 & 1.7042 \\
\hline High R\&D & 0.3992 & 1.2307 & 1.8762 & 2.7079 & 3.2325 & 0.7953 & 2.1744 & 2.3599 & 3.0102 & 2.6017 \\
\hline HML & -0.1945 & -0.3532 & -0.4568 & -0.1632 & 0.1714 & -0.3766 & -0.3977 & -0.4341 & -0.1336 & 0.0865 \\
\hline Mrkt. & -0.7008 & -0.0305 & 0.3983 & 1.1086 & 1.2712 & -1.5293 & -0.0658 & 0.7818 & 1.9867 & 1.6191 \\
\hline
\end{tabular}


Table 6: This table shows results from predictive $R \& D$ intensity regressed on one-period lagged Debt/GDP and Tobin's Q. Regressions are performed on each R\&D portfolio. Standard errors are based on Newey-West (1987) standard errors. In particular the regression is the following, where $\mathrm{h}$ is the length of the predictive horizon: $\sum_{i=1}^{h} R D_{t+i}=$ $\beta_{0}+\beta_{1} B Y_{t}+\beta_{2} Q_{t}+\epsilon_{t+h}$

\begin{tabular}{rrrrrrrr} 
& \multicolumn{2}{c}{ Debt/GDP } & & \multicolumn{2}{c}{ Tobin Q } & \\
\cline { 2 - 3 } Low R\&D & -0.0045 & -2.0784 & & 0.0001 & 0.4338 & & 0.0343 \\
2 & -0.0079 & -1.5183 & & -0.0017 & -5.2238 & & 0.0460 \\
3 & -0.0052 & -0.8028 & & -0.0003 & -0.3468 & & 0.0063 \\
4 & 0.0008 & 0.0551 & & 0.0053 & 3.0537 & & 0.0449 \\
5 & -0.0259 & -0.9016 & & 0.0006 & 0.2172 & & 0.0100 \\
6 & -0.0312 & -0.8615 & & 0.0075 & 2.3907 & & 0.0476 \\
7 & -0.0499 & -1.3405 & & 0.0028 & 0.9140 & & 0.0283 \\
8 & -0.0284 & -1.1199 & & 0.0131 & 4.5129 & & 0.0443 \\
9 & -0.0012 & -0.0342 & & -0.0027 & -0.5221 & & 0.0022 \\
Highn R\&D & -0.2802 & -2.1883 & & -0.0108 & -1.1182 & & 0.0301 \\
HML & -0.1424 & -2.2196 & & -0.0054 & -1.1172 & & 0.0309
\end{tabular}

Table 7: This table shows results from predictive US real GDP growth regressed on lagged P/D, Debt/GDP, and market volatility proxy. Standard errors are based on Newey-West (1987) standard errors.

\begin{tabular}{rrrrrrrrr} 
& $\mathrm{T}+1$ & $\mathrm{~T}+2$ & $\mathrm{~T}+4$ & $\mathrm{~T}+8$ & $\mathrm{~T}+20$ & $\mathrm{~T}+24$ & $\mathrm{~T}+28$ & $\mathrm{~T}+32$ \\
\cline { 2 - 9 } Constant & 0.0209 & 0.0304 & 0.0486 & 0.0866 & 0.1867 & 0.2186 & 0.2566 & 0.2966 \\
& -0.0049 & -0.0073 & -0.0121 & -0.0184 & -0.0241 & -0.0229 & -0.0222 & -0.0216 \\
$\mathrm{P} / \mathrm{D}$ & 4.2211 & 4.1537 & 4.0151 & 4.7069 & 7.7518 & 9.5616 & 11.5694 & 13.7512 \\
& 0.0000 & -0.0001 & -0.0002 & -0.0006 & -0.0014 & -0.0016 & -0.0018 & -0.0021 \\
& -0.0001 & -0.0001 & -0.0002 & -0.0003 & -0.0004 & -0.0004 & -0.0005 & -0.0005 \\
Debt/GDP & -0.2743 & -0.6203 & -1.2233 & -2.1648 & -3.3456 & -3.6147 & -3.8793 & -4.5561 \\
& -0.0022 & -0.0001 & 0.0049 & 0.0149 & 0.0570 & 0.0677 & 0.0712 & 0.0827 \\
& -0.0090 & -0.0133 & -0.0211 & -0.0312 & -0.0339 & -0.0327 & -0.0318 & -0.0297 \\
Mrkt. Vol. & -0.2475 & -0.0058 & 0.2321 & 0.4762 & 1.6821 & 2.0683 & 2.2420 & 2.7805 \\
& -0.1924 & -0.2502 & -0.2280 & -0.1992 & -0.1757 & 0.0030 & -0.1324 & -0.4030 \\
& -4.2626 & -4.0568 & -0.0719 & -0.1052 & -0.1971 & -0.2153 & -0.2170 & -0.2323 \\
& & & -3.1719 & -1.8927 & -0.8916 & 0.0138 & -0.6103 & -1.7349 \\
$R^{2}$ & 0.0715 & 0.0698 & 0.0460 & 0.0721 & 0.1708 & 0.2078 & 0.2346 & 0.3071
\end{tabular}


Table 8: This table presents the parameters used in the high Debt/GDP baseline calibration.

\begin{tabular}{rr} 
High Debt/GDP Case \\
\hline$\beta$ & 0.9960 \\
$\psi$ & 1.2000 \\
$\gamma$ & 10.0000 \\
$\xi$ & 0.4700 \\
$\nu$ & 1.6500 \\
$\alpha$ & 0.4236 \\
$\rho$ & 0.9925 \\
$\chi$ & 0.3300 \\
$\phi$ & 0.9600 \\
$\eta$ & 0.8300 \\
$\delta$ & 0.0200 \\
$\zeta$ & 13.3000 \\
$A_{z}$ & -1.0000 \\
$A_{\Gamma}$ & 10.0000 \\
$A_{B / Y}$ & 4.6500 \\
$\sigma_{B / Y}$ & 0.0330 \\
$\sigma$ & 0.0200 \\
$\sigma_{G / Y}$ & 0.0080 \\
$\rho_{G / Y}$ & 0.9800 \\
$\rho_{B / Y}$ & 0.9937
\end{tabular}


Table 9: This table shows annualized model statistics under two Debt/GDP scenarios. All growth and return statistics are in logs. $\tau$, Gov./GDP, and Debt/GDP variables are in levels. Means and standard deviations have been multiplied by 100. Statistics were obtained using a long simulated model path of 50,000 periods. The High Debt/GDP case was calibrated to deliver a deterministic steady state Debt/GDP level of $60 \%$ and volatility of $18 \%$. The Zero Debt/GDP case was calibrated to deliver a deterministic steady state Debt/GDP level of $0 \%$ and volatility of $18 \% . R_{d}-R_{f}$ is the excess return of the physical capital asset, $R_{r d}-R_{f}$ is the excess return of the R\&D sector asset, and $R_{m}-R_{f}$ is the excess return of the equity market, which is a market-value weighted average of the physical capital and R\&D assets.

\begin{tabular}{|c|c|c|c|c|c|c|}
\hline & \multicolumn{3}{|c|}{ High Debt/GDP Case } & \multicolumn{3}{|c|}{ Zero Debt/GDP Case } \\
\hline & Mean & Std & $\mathrm{AR}(1)$ & Mean & Std & $\mathrm{AR}(1)$ \\
\hline$\Delta y$ & 2.0129 & 2.3730 & 0.0905 & 1.9817 & 2.3701 & 0.0875 \\
\hline$\Delta z$ & 2.0136 & 4.0182 & 0.0343 & 1.9825 & 4.0166 & 0.0328 \\
\hline$\Delta s$ & 2.0132 & 3.6503 & 0.0186 & 1.9820 & 3.5682 & 0.0199 \\
\hline$S$ & 9.1271 & 0.9875 & 0.9859 & 9.4518 & 1.0089 & 0.9862 \\
\hline$\Delta i$ & 2.0137 & 3.2326 & 0.0746 & 1.9825 & 3.1944 & 0.0731 \\
\hline$\Delta c$ & 2.0124 & 1.6407 & 0.1894 & 1.9812 & 1.6536 & 0.1789 \\
\hline$R_{f}$ & 1.7612 & 0.5432 & 0.9923 & 1.7538 & 0.5313 & 0.9927 \\
\hline$R_{d}-R_{f}$ & 0.2778 & 1.0219 & 0.0043 & 0.0334 & 0.9296 & 0.0049 \\
\hline$R_{r d}-R_{f}$ & 0.6387 & 1.9356 & 0.0073 & 0.1636 & 1.7218 & 0.0143 \\
\hline$R_{c}-R_{f}$ & 2.1716 & 2.6845 & -0.0068 & 2.1334 & 2.6792 & -0.0068 \\
\hline Gov./GDP & 11.4827 & 0.3926 & 0.9783 & 11.4827 & 0.3926 & 0.9783 \\
\hline Debt/GDP & 58.9891 & 18.1546 & 0.9931 & -0.9113 & 18.6549 & 0.9931 \\
\hline$R_{m}-R_{f}$ & 0.3571 & 0.1285 & 0.0022 & 0.0481 & 0.1157 & 0.0040 \\
\hline$\tau$ & 19.8459 & 15.1305 & 0.0089 & 20.1889 & 15.4252 & 0.0084 \\
\hline
\end{tabular}


Table 10: This table shows results from a GMM estimation of a linear factor model using a long simulation (50,000 periods). We use a 2-asset cross-section where Low R\&D and High R\&D Betas correspond respectively to the Physical Capital and R\&D sector asset returns. The Debt/GDP price is the market price of risk. Pos. $\phi$ corresponds to a countercyclical debt policy, and Neg. $\phi$ corresponds to a procyclical debt policy. We consider siulated models where we have (1) all exogenous shocks are active, (2) no exogenous debt policy shock (only technology and government spending shocks), and (3) only an exogenous debt policy shock (no technology and government spendings shocks). Newey-West (1987) standard errors are used to construct t-statistics, which are reported underneath the point estimates.

Zero Debt/GDP

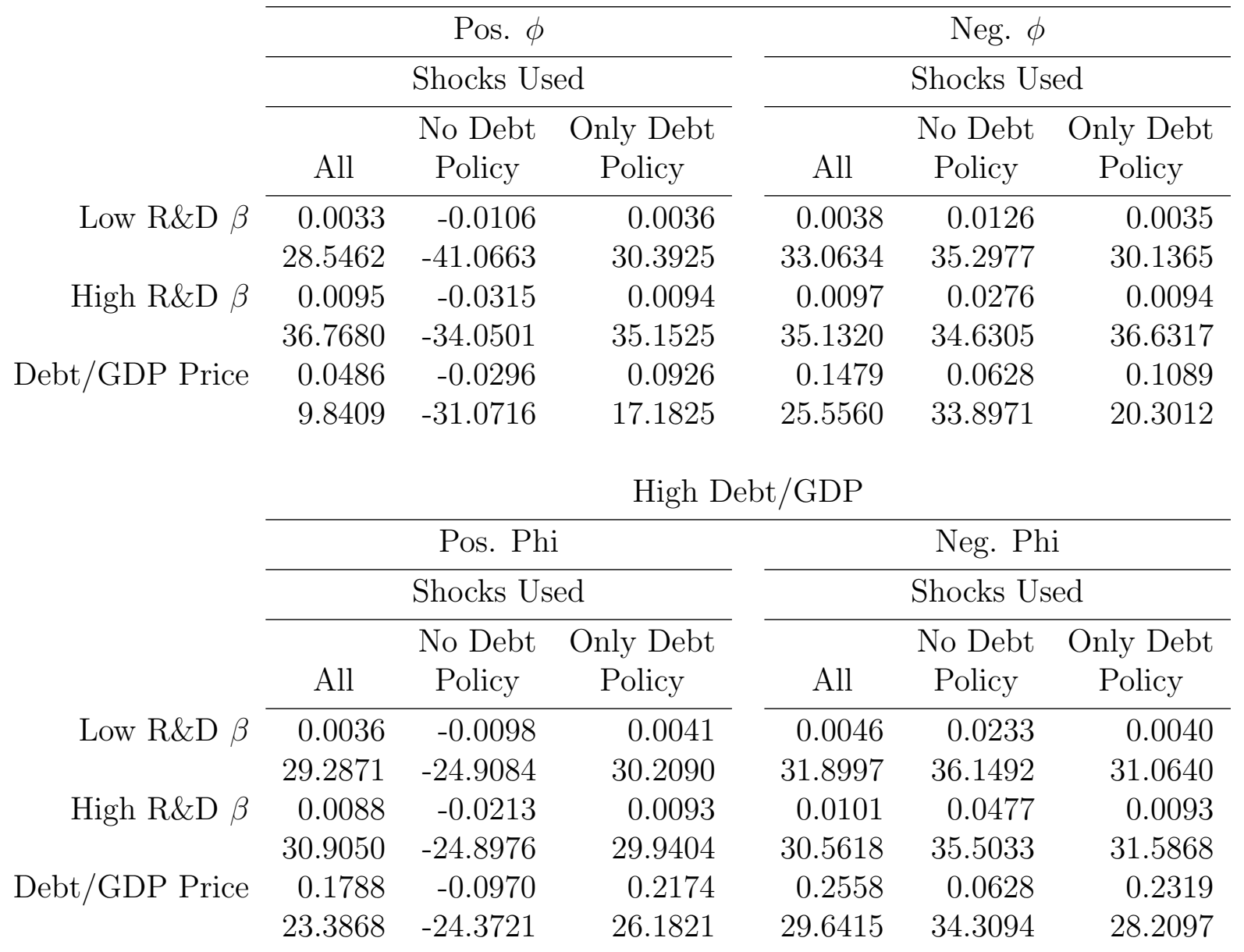


Table 11: This table shows results from predictive regressions of returns on Debt/GDP using a long simulated model path of 50,000 periods. Regressions are performed for the physical capital sector (low $R \& D$ ), the $R \& D$ sector (high $R \& D$ ), a portfolio that is long the $R \& D$ sector and short the physical capital sector (HML), and a value-weighted market of both sectors. The timing of the predictive regressions is based on cumulative future returns over quarters. The model is estimated under the high-Debt/GDP scenario. t-statistics are based on Newey-West (1987) standard errors.

\begin{tabular}{|c|c|c|c|c|c|c|c|c|c|c|}
\hline & \multicolumn{5}{|c|}{ Estimates } & \multicolumn{5}{|c|}{ t-stats } \\
\hline & $\mathrm{T}+1$ & $\mathrm{~T}+2$ & $\mathrm{~T}+4$ & $\mathrm{~T}+8$ & $\mathrm{~T}+20$ & $\mathrm{~T}+1$ & $\mathrm{~T}+2$ & $\mathrm{~T}+4$ & $\mathrm{~T}+8$ & $\mathrm{~T}+20$ \\
\hline & \multicolumn{10}{|c|}{ All Shocks } \\
\hline Low R\&D & 0.0041 & 0.0047 & 0.0060 & 0.0085 & 0.0154 & 15.7810 & 12.1112 & 9.2037 & 7.4141 & 6.4243 \\
\hline High R\&D & 0.0133 & 0.0176 & 0.0260 & 0.0427 & 0.0900 & 22.0361 & 19.2345 & 16.9856 & 15.5331 & 14.5838 \\
\hline HML & 0.0092 & 0.0129 & 0.0201 & 0.0343 & 0.0746 & 21.4304 & 19.7454 & 18.3367 & 17.2912 & 16.2430 \\
\hline \multirow[t]{2}{*}{ Market } & 0.0065 & 0.0080 & 0.0111 & 0.0172 & 0.0343 & 18.8501 & 15.4710 & 12.7947 & 11.1506 & 10.2959 \\
\hline & \multicolumn{10}{|c|}{ No Debt Policy Shock } \\
\hline Low R\&D & 0.0027 & 0.0030 & 0.0037 & 0.0052 & 0.0099 & 8.6175 & 6.4504 & 4.7798 & 3.8638 & 3.4656 \\
\hline High R\&D & 0.0102 & 0.0137 & 0.0207 & 0.0347 & 0.0750 & 15.7052 & 14.1372 & 12.9633 & 12.4238 & 12.5536 \\
\hline HML & 0.0075 & 0.0107 & 0.0170 & 0.0295 & 0.0651 & 19.41 & 18.5140 & 17.8493 & 17.5690 & 17.7293 \\
\hline \multirow[t]{2}{*}{ Market } & 0.0043 & 0.0052 & 0.0071 & 0.0110 & 0.0224 & 10.3586 & 8.4556 & 6.9957 & 6.2272 & 5.9922 \\
\hline & \multicolumn{10}{|c|}{ Only Debt Policy Shock } \\
\hline Low R\&D & 0.0044 & 0.0051 & 0.0066 & 0.0094 & 0.0172 & 16.3549 & 12.7424 & 9.8571 & & 7.0770 \\
\hline High R\&D & 0.0140 & 0.0184 & 0.0272 & 0.0444 & 0.09 & 23.24 & 20.3743 & 18.0597 & 16.5680 & 15.8761 \\
\hline HML & 0.0096 & 0.0133 & 0.0206 & 0.0350 & 0.0761 & 23.8372 & 21.9384 & 20.3663 & 19.2412 & 18.3966 \\
\hline Market & 0.0069 & 0.0086 & 0.0119 & 0.0185 & 0.0368 & 19.5337 & 16.1930 & 13.5221 & 11.8389 & 11.1147 \\
\hline
\end{tabular}

